\title{
Microstructure Analysis and Mechanical Properties of Low Alloy High Strength Quenched and Partitioned Steel
}

\author{
Farnoosh Forouzan $^{1, a}$, Suresh Gunasekaran ${ }^{1, b}$, Ali Hedayati ${ }^{1, c}$, \\ Esa Vuorinen ${ }^{1, \mathrm{~d}}$ and Frank Mücklich ${ }^{2, \mathrm{e}}$ \\ 1 Department of Engineering Sciences and Mathematics, Luleå University of Technology, \\ SE-97187 Luleå, Sweden \\ ${ }^{2}$ Department for Materials Science, Functional Materials, Saarland University, D-66041 \\ Saarbrücken, Germany \\ afarnoosh.forouzan@Itu.se, bsuresh.gunasekaran@icloud.com, cali.hedayati@ltu.se, \\ desa.vuorinen@Itu.se, ${ }^{\mathrm{e}}$ muecke@matsci.uni-sb.de
}

Keywords: AHSS, Gleeble, Quenching and partitioning (Q\&P), X-ray, mechanical properties

\begin{abstract}
Gleeble study of the quenching and partitioning (Q\&P) process has been performed on Domex 960 steel $(\mathrm{Fe}, 0.08 \% \mathrm{C}, 1.79 \% \mathrm{Mn}, 0.23 \% \mathrm{Si}, 0.184 \% \mathrm{Ti}$, and $0.038 \% \mathrm{Al})$. The effect of different Q\&P conditions on microstructure and mechanical properties were investigated. The aim of the process is to produce a fine grained microstructure for better ductility and controlled amounts of different micro-constituents to increase the strength and toughness simultaneously. Three different quenching temperatures, three partitioning temperatures and three partitioning times have been selected to process the 27 specimens by Gleeble ${ }^{\circledR} 1500$. The specimens were characterized by means of OM, SEM, XRD, hardness and impact tests. It was found that, fine lath martensite with retained austenite is achievable without high amount of $\mathrm{Si}$ or $\mathrm{Al}$ in the composition although lack of these elements may cause the formation of carbides and decrease the available amount of carbon for partitioning into the austenite. The hardness increases as the quenching temperature is decreased, however, at highest partitioning temperature $\left(640^{\circ} \mathrm{C}\right)$ the hardness increases sharply due to extensive precipitate formation.
\end{abstract}

\section{Introduction}

Significant research efforts have been directed towards the development of advanced high-strength steels (AHSS). The main objective has been to obtain a good combination of strength and ductility. AHSS steels are usually multiphase and, thus the combination of different phases (ferrite, martensite, retained austenite (RA), etc.) leads to unique mechanical properties. The martensite and bainite constituents contribute to an increase of strength, whereas RA provides an improvement of ductility [1]. The microstructural heterogeneity results also in significant stress and strain partitioning among the micro-constituents during plastic deformation. The thermal processing route, "quenching and partitioning" (Q\&P), has been used for production of martensitic microstructures containing enhanced levels of retained austenite caused by carbon diffusion from martensite into austenite. Elements such as $\mathrm{Si}$ or $\mathrm{Al}$ hinder the carbide formation in steels. [2]. The mechanical behaviour depends on morphology, distribution and mechanical properties of the individual phases [3]. The Q\&P processing technique can also give a higher transformation rate in different manufacturing processes like press hardening, welding, etc. [4]. Initial studies on welding of a spring steel showed that it is possible to control the hardness in the fusion zone (FZ) and the part of the heat affected zone (HAZ) which is subjected to a risk of martensite formation at the end of the welding process. The results showed that a quenching process producing $50 \%$ martensite followed by partitioning during 90 seconds could restore the same hardness in the FZ and HAZ as conventional pre- and post-heat treatments lasting $30+30$ minutes [5].

The aim of this study has been to investigate the effects of using different Q\&P variables during welding of modern thermo-mechanically produced steel by simulating the process with Gleeble test and study the amount of retained austenite, microstructure and mechanical properties achieved after these treatments. 


\section{Experimental procedure}

Table 1 shows the chemical composition of the AHSS, Domex 960, produced by SSAB Company.

Table 1. Chemical composition of Domex 960.

\begin{tabular}{|c|c|c|c|c|c|c|c|}
\hline $\mathrm{C} \%$ & $\mathrm{Si} \%$ & $\mathrm{Mn} \%$ & $\mathrm{P} \%$ & $\mathrm{~S} \%$ & $\mathrm{Al} \%$ & $\mathrm{Ti} \%$ & $\mathrm{Mo} \% \mathrm{Cr} \% \quad \mathrm{Ni} \% \quad \mathrm{Cu} \% \mathrm{~V} \% \mathrm{~N} \% \mathrm{Fe}$ \\
\hline 0.082 & 0.23 & 1.79 & 0.008 & 0.001 & 0.038 & 0.184 & 0.5030 .0640 .2960 .0160 .0120 .004 Balance \\
\hline
\end{tabular}

Specimens $(75 \times 5.5 \mathrm{~mm})$ were cut from $6 \mathrm{~mm}$ thick plates and subjected to Q\&P heat treatment cycles in the Gleeble ${ }^{\circledR} 1500$ simulator. The process started with heating to above the $A_{3}$ temperature $\left(1350{ }^{\circ} \mathrm{C}\right.$ for $\left.2 \mathrm{sec}\right)$ and was followed by quenching to one of $3\left(255,355\right.$ and $\left.420{ }^{\circ} \mathrm{C}\right)$ temperatures. Then the samples were reheated with a heating rate of $80{ }^{\circ} \mathrm{C} / \mathrm{s}$, kept isothermally at $440{ }^{\circ} \mathrm{C}$ (close to Ms), $540{ }^{\circ} \mathrm{C}$ (between Ms and Bs) or $640{ }^{\circ} \mathrm{C}$ (above Bs) for 2,5 or 50 seconds for partitioning and finally quenched with a rate of $80{ }^{\circ} \mathrm{C} / \mathrm{s}$ to room temperature.

After regular grinding and polishing steps until $0.05 \mu \mathrm{m}$, samples were etched by Nital $3 \%$ and scanning electron microscopy (SEM) was done by JSM $6460 \mathrm{LV}$, with accelerating voltage of $15 \mathrm{kV}$. X-ray diffraction (XRD) analysis was performed using monochromatic $\mathrm{Cu}-\mathrm{K} \alpha$ radiation at $40 \mathrm{KV}$ and $45 \mathrm{~mA}$ to scan the angular $2 \theta$ range of $35^{\circ}$ to $100^{\circ}$. Data was analysed using High Score Plus software (vers.3.0.1). Micro Vickers hardness measurements were performed on the specimens using the load of $0.5 \mathrm{~kg}$. Impact tests were carried out according to the standard EN ISO 6892$1: 2009$.

\section{Results}

The microstructural investigation of the samples show bulky micro-constituents which are most likely tempered martensite with titanium nitride precipitates inside martensite and retained austenite in flat dark areas with fine bainitic ferrite laths. Comparison of microstructures of the samples quenched at same temperature in Fig. 1 implies that since the amounts of martensite in all conditions are approximately the same, the longer the partitioning time and higher the temperature, the higher the number and size of precipitates and thicker the bainitic laths are. However, the particles cannot be seen in Fig. 1(i) which is heated at $640{ }^{\circ} \mathrm{C}$ for 50 s probably because larger precipitates can be formed at the grain boundaries and be hidden there. In addition, the amount of stabilized retained austenite at room temperature after the heat treatment cycle increases as the temperature or time increase in samples partitioned at $440{ }^{\circ} \mathrm{C}$ or $540{ }^{\circ} \mathrm{C}$ but for the samples partitioned at $640{ }^{\circ} \mathrm{C}$ the retained austenite transforms to other phases. 

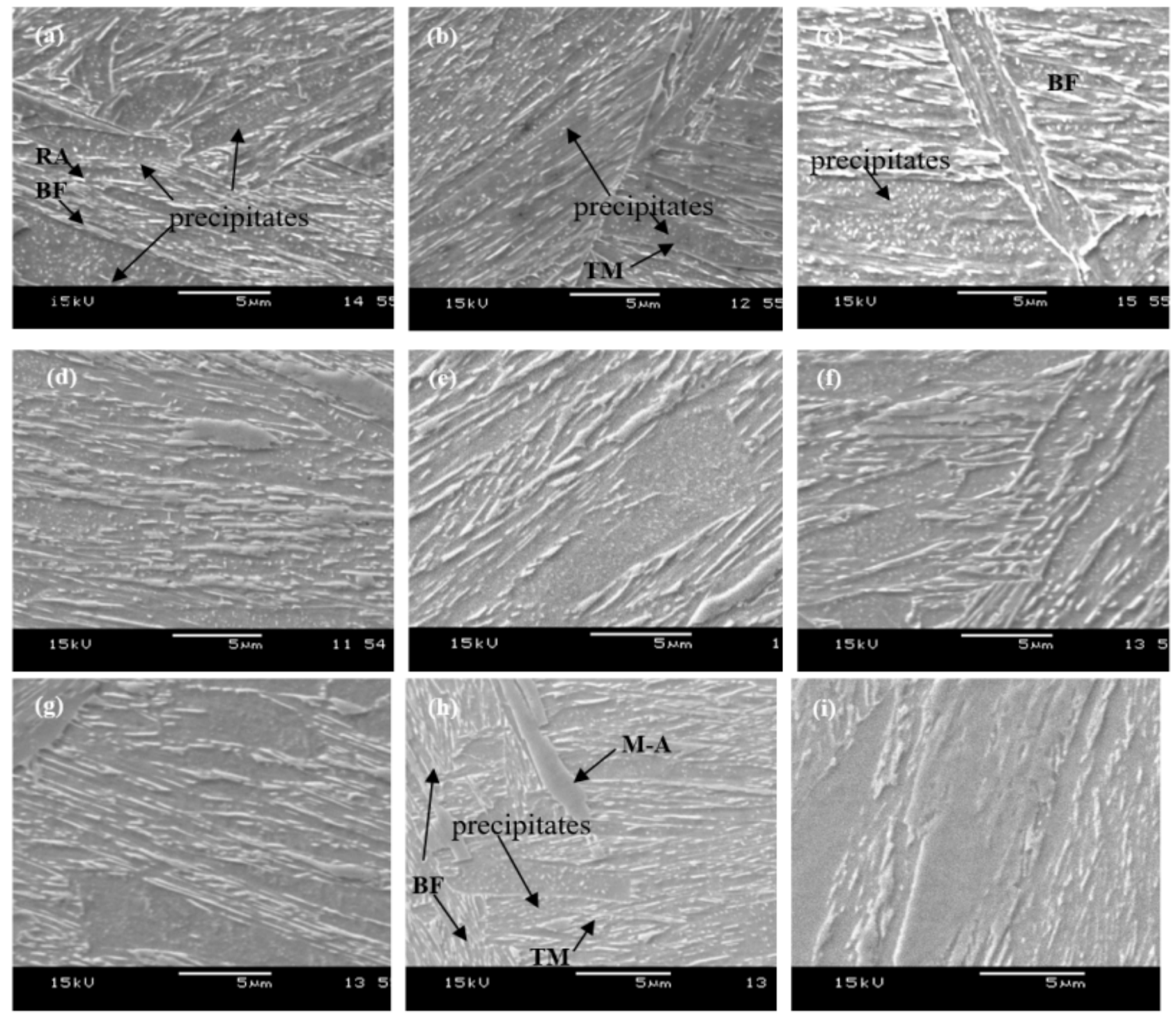

Figure 1. The XRD analyze of one of the softest samples shows around 6\% austenite, . In Fig. 2(a) the first two peaks around $40^{\circ}$ and $42^{\circ}$ shows one type of titanium nitride and all other peaks are related to retained austenite $(\gamma)$ and ferrite/martensite $(\alpha)$. It is hard to distinguish martensite from ferrite with XRD since their peaks are expected to be found at the same angles or very close to each other.
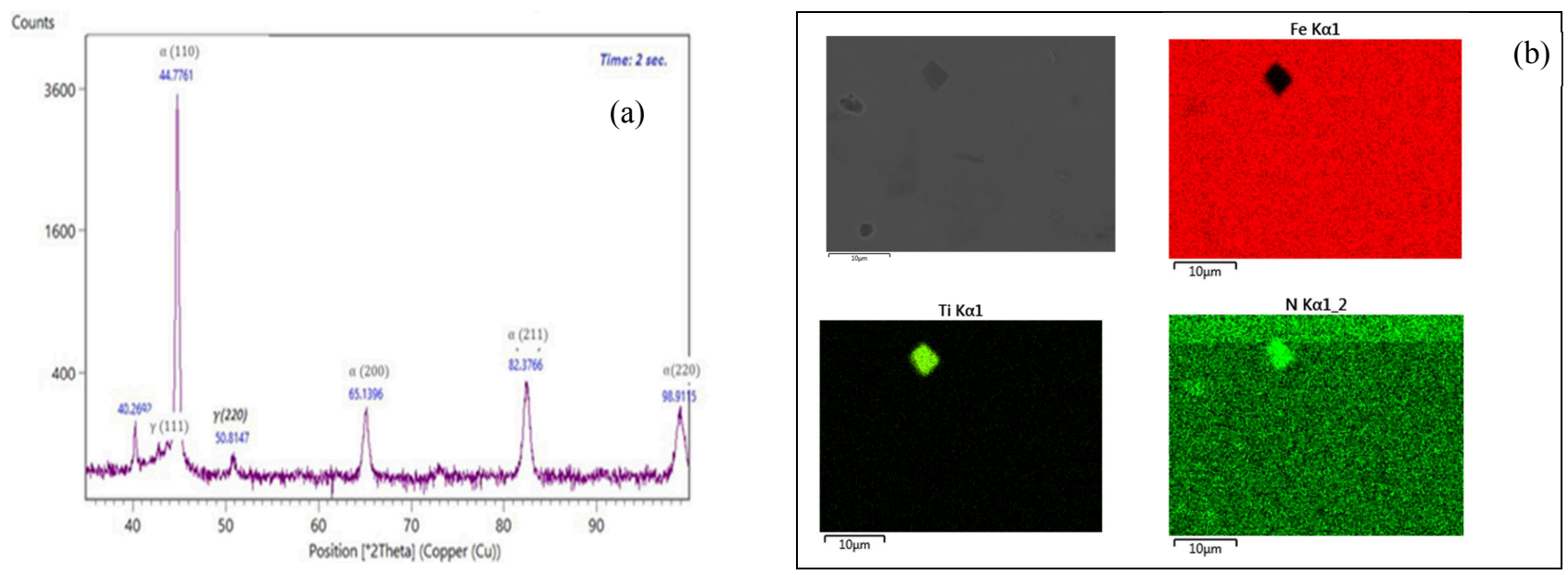

Figure 2. (a) XRD pattern of the sample quenched at $355{ }^{\circ} \mathrm{C}$ and heated at $540^{\circ} \mathrm{C}$ for 2 seconds (b) EDS result of sample quenched at $355^{\circ} \mathrm{C}$ and partitioned at $640^{\circ} \mathrm{C}$ for 50 seconds. 
Only the martensite diffraction peaks for the (002) and (112) planes around $2 \theta=60^{\circ}$ and $78^{\circ}$ respectively, can distinctly be separated from the austenite and ferrite peaks but these peaks are weak and cannot be seen in these samples. It means that most of the martensite in the structure is tempered and during the last quench no or very small amount of retained austenite is transformed to martensite which is not detectable in XRD pattern. Also characterization of the precipitates with EDS in Fig 2(b), confirms the formation of titanium nitrides during partitioning.

Fig 3(a) shows the hardness values of the samples. The hardness is higher for all treated samples in comparison with the received material $\left(320 \mathrm{HV}_{0.5}\right)$. Typically, increasing the partitioning time or temperature will decrease the hardness value as a result of martensite tempering and partitioning of the adequate carbon to retained austenite and stabilize that. But, samples which are partitioned at $640{ }^{\circ} \mathrm{C}$ for $50 \mathrm{~s}$ have significantly higher hardness since this condition provides enough time for the hardening by precipitation to counteract the tempering effect. The energy absorbed during Charpy impact test, shows that samples partitioned at $640^{\circ} \mathrm{C}$ have the lowest results while the samples isothermally heated at $540^{\circ} \mathrm{C}$ show the best results, see Fig. 3(b).
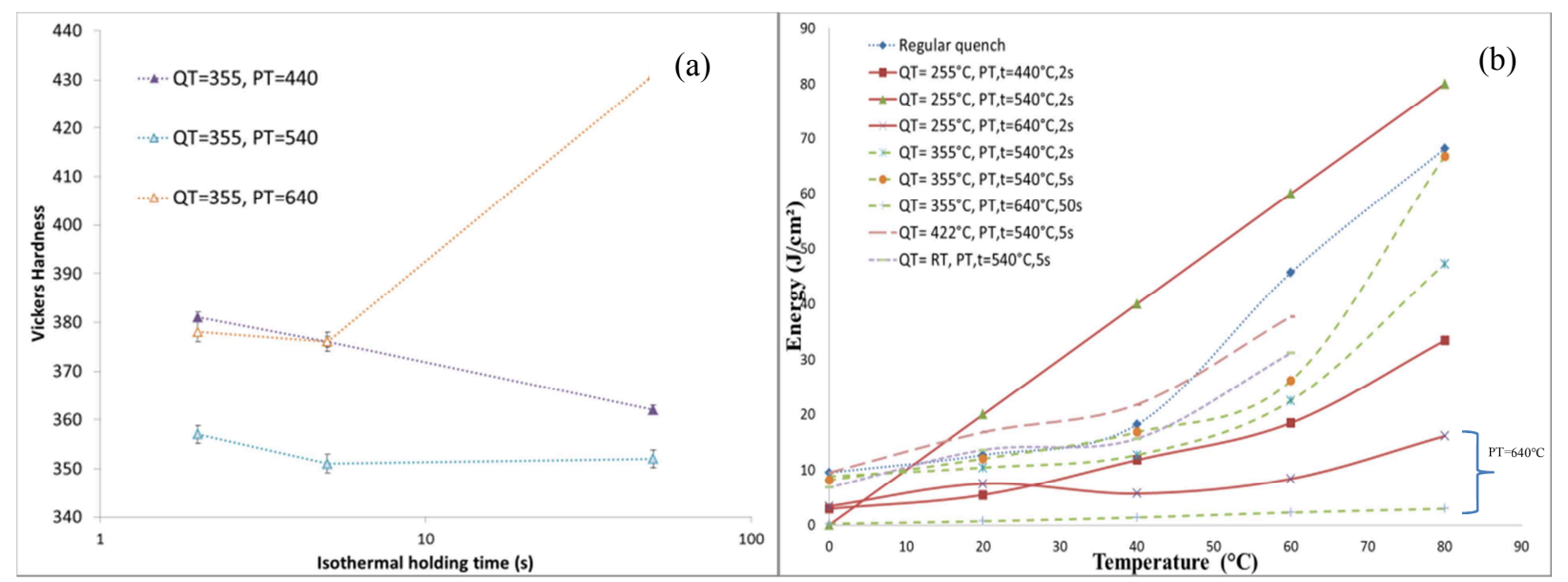

Figure 3. (a) Hardness results and (b) Impact toughness test results of different samples.

\section{Conclusions:}

1) The SEM analyse reveals the presence of tempered martensite with precipitates (titanium nitride) inside, bainite laths and bulky retained austenite and/or untempered martensite for all samples. The amount and size of each micro-constituent depends on the Q\&P conditions.

2) The hardness values of all treated samples were higher than the base material due to the formation of martensite and precipitates in all cases. The specimens which were partitioned at 640 ${ }^{\circ} \mathrm{C}$ for 50 s have noticeably higher hardness than the other samples because of the increasing amount of precipitates in the structure at that temperature.

3) Although there are just small amounts of $\mathrm{Si}$ and $\mathrm{Al}$ which can slow down the carbide formation, the austenite can be stabilised by selecting proper Q\&P conditions.

4) Impact toughness results show more brittle behaviour for samples partitioned at $640{ }^{\circ} \mathrm{C}$ even for a very short partitioning time of 2 seconds but the values for samples in which the partitioning temperature is below the $\mathrm{B}_{\mathrm{s}}$ temperature are much better. 


\section{References}

[1] Speer JG, De Moor E, Clarke AJ. Critical Assessment 7: Quenching and partitioning. Materials Science and Technology 2015 Jan 2015;31(1):3-9.

[2] de Diego-Calderón I, De Knijf D, Monclús MA, Molina-Aldareguia JM, Sabirov I, Föjer C, et al. Global and local deformation behavior and mechanical properties of individual phases in a quenched and partitioned steel. Materials Science and Engineering: A 2015 4/10;630(0):27-35.

[3] Chen JH, Kikuta Y, Araki T, Yoneda M, Matsuda Y. Micro-fracture behaviour induced by M-A constituent (Island Martensite) in simulated welding heat affected zone of HT80 high strength low alloyed steel. Acta Metallurgica 1984 10;32(10):1779-1788.

[4] Seo E, Cho L, De Cooman B. Application of Quenching and Partitioning (Q\&P) Processing to Press Hardening Steel. Metallurgical and Materials Transactions A 2014;45(9):4022-4037.

[5] Vuorinen E, Bax B, Navara E. Weldability of hardenable silicon alloyed spring steel. Conference proceedings of Acta Metallurgica Slovaca Conference, No 14, 2010, 247-254. 